\title{
A clinical study on indications for caesarean section among primigravida in a tertiary care centre
}

\author{
Nair R.V. ${ }^{1}$, Sowbharnika C.P. ${ }^{2}$, Seetha P.M. ${ }^{3}$ \\ ${ }^{1}$ Dr. Rema V. Nair, Professor, ${ }^{2}$ Dr. Sowbharnika C.P., Junior Resident ${ }^{3}$ Dr. Seetha P.M., Professor, all authors are \\ affiliated with Department of Obstetrics and Gyanecology Sree Mookambika Institute of Medical Sciences, \\ Kulasekharam, Kanyakumari Tamil Nadu, India.
}

Corresponding Author: Dr. Rema. V. Nair, Professor, Department of Obstetrics and Gyanecology, Sree Mookambika Institute of Medical Sciences Kulasekharam, Kanyakumari, India. E-mail: vishnusastha@gmail.com

\begin{abstract}
Background: The Primary caesarean section (CS) delivery rate is increasing due to public interest to avoid fetal complications and acceptance by most of the couple to complete their family with one or two children. High cesarean birth rates are an issue of international public health concern. Worries over such increases have led the World Health Organization to advise that Cesarean Section (CS) rates should not be more than $15 \%$, with some evidence that CS rates above $15 \%$ are not associated with additional reduction in maternal and neonatal mortality and morbidity. Aims and Objectives: To find out the indications of caesarean section among primigravida in a tertiary care centre. Methods: A total of 100 cases were selected for the study who regularly attended outdoor (Booked) and admitted, those who booked in antenatal clinic but admitted as emergency. Results: The most common age group in the present study was 20-25 years (45\%). Among the study cases, $80 \%$ were booked, $20 \%$ were unbooked. Conclusion: Obstetric factors occurring around birth, including obstructed labor and fetal distress were the main reasons leading to Cesarean Section rather than background characteristics assumed to be a risk. The results imply that there is a need for timely and accurate screening of women during obstetric care and, decision to perform cesarean section should be based on clear, compelling and wellsupported justifications. Early referral instead of late referral from the periphery hospitals to the tertiary hospital is necessary for trial of vaginal delivery.
\end{abstract}

Keywords: Primigravida, Caesarean section, Booked case

\section{Introduction}

Caesarean section is the commonest obstetric operative procedure worldwide $[1,2]$. When used appropriately Caesarean sections can improve infant and/or maternal outcomes. However, when used inappropriately the potential harm may exceed the potential benefit of $\mathrm{C}$ section. C-sections cost more than vaginal births and can result in increased risk to mother and baby $[2,3]$.

There is a growing concern that Caesarean rates have been rising for all women in the world regardless of medical condition, age, race, or gestational age. International concern over such increases have prompted the World Health Organization to suggest that CS rates should not exceed $15 \%$ [4], with some evidence indicating caesarean section rates above $15 \%$ are not associated with additional reduction in maternal

Manuscript received: $8^{\text {th }}$ June 2019

Reviewed: $18^{\text {th }}$ June 2019

Author Corrected: $25^{\text {th }}$ June 2019

Accepted for Publication: $30^{\text {th }}$ June 2019 and neonatal mortality and morbidity [5, 6]. Modern obstetrics practice for medical, social, economic and legal reasons have witnessed an increase in the primary caesarean section rates everywhere [7]. While the Caesarean section rate ranges between 12 and $86 \%$ across studies done in developed countries $[6,7]$ and the rate in developing countries vary between $2 \%$ and $39 \%$. No standard classification system exists for Caesarean indications Caesarean sections are performed for maternal or fetal complications.

The worldwide increase in the use of obstetric interventions since the 1970 s is a present cause of concern as interventions may not only reduce morbidity and mortality but also impose risks of adverse events or further interventions [8]. One of the most intrusive interventions, cesarean section (CS), has become increasingly common in most of the industrialized world [9]. The World Health Organization (WHO) and 


\section{Original Research Article}

Organization for Economic Co-operation and Development (OECD) have raised concerns regarding the frequent and increasing use of CS [8, 9]. Research studies have consistently found an association between the increase in maternal age and an increase in CS [10, 11]. As morbidity tends to increase with age, any group of women with advanced maternal age will include more individuals with age-related prenatal risk factors such as hypertension [12] diabetes mellitus and high Body Mass Index (BMI) compared with a similar group of younger pregnant women $[13,14]$.

Furthermore, studies have found that more women in the advanced age-group develop pregnancy-related complications including gestational diabetes [15], preeclampsia, and placenta previa [16]. Most common causes for maternal deaths are severe 3 bleeding, infections, high blood pressure during pregnancy, these accounts for almost $75 \%$ of maternal deaths.

Aims and Objectives: To find out the indications of caesarean section among primigravida in a tertiary care centre.

\section{Materials and Methods}

Study design: Cross sectional study

Study setting: Department of Obstetrics \& Gynaecology, Sree Mookambika Institute of Medical Sciences, Tamil Nadu.

Approximate duration of study: One year
Detailed description of the groups: Antenatal patients who regularly attended outdoor (Booked) and admitted those who booked in antenatal clinic but admitted as emergency.

Data collection procedure: Thorough history taking, examination and clinical assessment were done in all the study cases and recorded all information found important for the study.

Investigations needed were carried out. All the mother and neonates were advised to come in Gynaecology outpatient department clinic for check-up and Paediatric outpatient department clinic for immunization of the baby after 6 weeks.

After proper assessment and evaluation primary caesarean section deliveries were performed as per necessity

Total sample size of the study: 100 cases (All the cases who fulfilled the inclusion criteria for the period of December 2017-December 2018 was taken into the study for consideration there for no sample size

Sampling technique used in study: Systemic random sampling

Inclusion criteria: All the primigravida who underwent c-section

Exclusion criteria: Multigravidas are excluded from the study.

\section{Results}

It has been seen that most common age group in the present study was $20-25$ years (45\%). Among the study cases, $80 \%$ were booked, and 20\% were unbooked. All (100\%) the women for present study were primigravida and mode of delivery was lower segment caesarean section. The average duration of labour was 10 hours 35 minutes.

Out of 100 selected cases of primary caesarean section $18 \%$ were elective and $82 \%$ were emergency after failure of trial of vaginal delivery.

Out of elective cases 2 patient had contracted pelvis. Other indications were pre-eclamptic toxaemia in 1 case, borderline disproportion in 2 patients, breech presentation in 5 cases and 3 in postdated pregnancy and 2 in oligohydramnios and 3 in transverse lie with placenta praevia. Emergency caesarean section were done in 52 fetal distress cases, 1 disproportion, 4 premature rupture of membrane, 2 each in breech, dystocia and antepartum haemorrhage, 2 decrease fetal movement, and 5 in brow, 3 in footling and 2 in cord presentation cases.

Table-1: Mode of operation

\begin{tabular}{|c|c|c|}
\hline Mode of operation & Number of patients & Percentage \\
\hline Elective LSCS & 18 & 18 \\
\hline Emergency LSCS & 82 & 82 \\
\hline
\end{tabular}


Original Research Article

Table-2: Indication for caesarean section delivery

\begin{tabular}{|l|c|c|}
\hline Type of section with indication & Number of patients & Percentage \\
\hline Elective & 18 & 2 \\
\hline Contracted pelvis & 2 & 3 \\
\hline Transverse lie with APH & 3 & 5 \\
\hline Breech & 2 & 2 \\
\hline Disproportion & 1 & 1 \\
\hline Severe PIH & 3 & 3 \\
\hline Postdated & 2 & 2 \\
\hline Oligohydramnios & 82 & 82 \\
\hline Emergency & 52 & 52 \\
\hline Fetal distress & 4 & 4 \\
\hline PROM & 3 & 3 \\
\hline IUGR with Oligohydramnios & 5 & 5 \\
\hline Brow & 3 & 3 \\
\hline Footling & 2 & 2 \\
\hline Cord presentation & 4 & 4 \\
\hline Induction failure & 2 & 2 \\
\hline Less fetal movement & 1 & 1 \\
\hline Disproportion & 2 & 2 \\
\hline Cervical dystocia & 2 & 2 \\
\hline Breech presentation & 2 & 2 \\
\hline APH & & \\
\hline
\end{tabular}

\section{Discussion}

For the last 30 years, there has been a public concern about increasing caesarean section rates [17]. The increase has been a global phenomenon, the timing and rate of the increase has differed from one country to another, and marked differences in rates persist [18]. While analyzing the caesarean section rate, the number of caesarean section performed should be simple to determine but the indications will be more difficult to standardize. There should be one main indication rather than a list of indications, using an agreed standard hierarchical system [19].

As shown in this study, when analyzing indication for CS rates, the main contributing factor was fetal distress which alone contributed to $52 \%$. Cesarean section significantly reduces maternal and perinatal mortality. Obstetric factors occurring around birth, including obstructed labor and fetal distress were the main reasons leading to caesarean section, The results imply that there is a need for timely and accurate screening of women during obstetric care and, decision to perform caesarean section should be based on clear, compelling and well-supported justifications. Like studies reported in different areas mothers reported as having pregnancy risk factors like diabetes and hypertension were at higher odds of undergoing CS delivery in this study [20, 21]. Presences of abnormal presentations, big babies which cause Cephalopelvic disproportion or malposition, are also consistently reported in other studies $[22,23]$. Another possible factor driving the rise of CS rates could be doctors' avoidance of potential practice risks.

A decision on the use of CS was often made during the third trimester of the pregnancy or during the process of labour. Low maternal childbirth self-efficacy was also a significant risk factor associated with maternal request for CS among primiparous women. Similarly, the chance of undergoing cesarean section would increase as age of the mother increases [24, 25, 26]. In this study, women's in age group of 15-19 years were 0.63 times less likely to undertake cesarean section as compared to age group of 20-34 years. The effect of 
Original Research Article

age in this study could be explained by the possibility of pregnancy complication increment by age [27, 28]. Presences of abnormal presentations, big babies which cause Cephalo pelvic disproportion or malposition, are also consistently reported in other studies [29]. Cesarean section rates were overestimated since vaginal deliveries at the home and at non-health facilities may have been underreported. It is less likely that the number of cesarean sections were underreported since $c$ sections always happen in a multi specialty setup which will in turn always be reported, whereas most vaginal deliveries can be left unreported only few non-MSF health facilities provided cesarean sections.

Consistent with other studies, the one of the most frequent indication of CS observed in the present study was obstructed labor. This was mostly due to last moment reporting or transfer of women with obstructed labor to the reference hospital from the periphery. On the other hand, injudicious use of oxytocic drugs or unjustified induction with prostaglandins without prior assessment of risk factors like fetal size, presentation, stage of labor ,position and pelvic adequacy might also contribute for the observed over diagnosis of obstructed labor and subsequent emergency CS.

Consistent with a study done southern Ethiopia, the other most frequent indication of CS observed in this study was fetal distress. Fetal distress was diagnosed among 115 fetuses $[30,31]$. Although using retrospective analysis, 84 (73\%) fetuses were diagnosed to have non-reassuring fetal heart rate pattern. As none of the fetuses were monitored by continuous electronic fetal monitoring system, over diagnosis of fetal distress is expected. Precise interpretation of fetal heart tracing and use of fetal $\mathrm{PH}$ might be effective in reducing cesarean section rate. Otherwise, inaccurate diagnosis of fetal distress would lead to unjustified use of CS.

This high incidence of caesarean section delivery is due to better technique, better anaesthetics, different antimicrobial agents, blood transfusion facilities etc. However, it must be accepted that caesarean section delivery carries somewhere between 5 and 10 times more risk than that of vaginal delivery. Similar to the outcome of this study, a study done in Assam showed Out of 100 selected cases of primary caesarean section $15 \%$ were elective and $85 \%$ were emergency after failure of trial of vaginal delivery. Out of elective cases 1 patient had contracted pelvis. Other indications were pre-eclamptic toxaemia in 5 cases, borderline disproportion in 4 patients, breech presentation in 3 cases and 1 of each in postdated oligohydramnios and transverse lie with placenta praevia. Emergency caesarean section were done in 40 fetal distress, 7 preeclamptic toxaemia, 6 disproportion, 7 premature rupture of membrane, 5 each in breech, dystocia and antepartum haemorrhage, 4decrease fetal movement, 3oligohydramnios, and 1 each in brow, footling and cord presentation cases. Most common presentation was cephalic (88\%). Complications during labour were 4antepartum bleeding, 1 postpartum bleeding and 2loss of fetal movement. Intraoperative complications were also observed. One major challenge is that definitions are not standardized and indications can be multiple or related.

Cephalopelvic disproportion is the most common cause of obstructed labor. Other causes could include malpresentation (brow, transverse, or breech presentation). Labor is considered prolonged if not progressing according to a normal partogram. Identifying the most common indications for caesarean section is important to target prevention strategies. In particular, recognizing indications that are associated with maternal or fetal deaths can help reduce mortality.

The reasons for the increase in CS are multifactorial, but existing literature suggests that the increase is predominantly a result of advanced maternal age, particularly in nulliparous women.

Obstetric factors around birth, including obstructed labor and fetal distress were the main reasons leading to cesarean section rather than background characteristics assumed to be a risk. It should be taken into consideration that Cesarean section rates were overestimated since vaginal deliveries at the home and at non-health facilities may have been underreported. From the study it was revealed that vaginal delivery may be allowed in a good number of cases after proper assessment and under strict supervision.

\section{Conclusion}

From the study it was revealed that vaginal delivery may be allowed in a good number of cases after proper assessment and under strict supervision. Early referral instead of late referral from the periphery hospitals to the tertiary hospital is necessary for trial of vaginal delivery. Maternal morbidities seen in this study were mostly preventable. Similarly according to study done in Denmark cesarean section increased with increasing maternal age. Adjustment for maternal and obstetric risk factors had only a minor influence on the association. The association was stronger in nulliparous women compared to multiparous women. Given the lack of 


\section{Original Research Article}

impact of demographic and health risks on the relationship between maternal age and cesarean section, the authors suggest obstetric culture could be added to the list of risk factors for a cesarean.

Future research on obstetric culture is recommended as are studies on a possible age-related decrease in the ability to maintain the progression of labour.

Funding: Nil, Conflict of interest: Nil

Permission from IRB: Yes

\section{References}

1. National Collaborating Centre for Women's and Children's Health. Caesarean section Guideline. Royal College of Obstetricians and Gynaecologists, 27 Sussex Place: RCOG Press; 2004.

2.Shamshad B. Factors Leading To Increased Caesarean Section Rate. Gomal J Med Sci. 2008;6:1.

3. Panditrao S. Intra-operative difficulties in repeat caesareansections. J Obstet Gynecol India. 2008;58(6): 507-10.

4. Bailey P, Lobis S, Maine D, Fortney JA. Monitoring emergency obstetric care: a handbook. World Health Organization; 2009.

5.Althabe F, Belizán JM. Caesarean section: the paradox. Lancet. 2006;368(9546):1472-3. DOI:10.1016/ S0140-6736(06)69616-5

6. Abu Anza SH, Abu Omar AA. Frequency rate and indications of cesarean sections at Prince Zaid bin Al Hussein Hospital-Jordan. J Royal Med Ser. 2012; 102 (354): 1-5.

7. Betrán AP, Merialdi M, Lauer JA, Bing-Shun W, Thomas J, Van Look $P$, et al. Rates of caesarean section: analysis of global, regional and national estimates. Paediatr Perinat Epidemiol. 2007; 21(2):98113. doi:10.1111/j.1365-3016.2007.00786.x

8. Organization for Economic Co-operation and Development O. Health at a Glance 2015: OECD Indicators. OECD Publishing, Paris: OECD; 2015.

9. Organization WH. WHO Statement on Caesarean Section Rates. World Health Organization, Geneva, Switzerland: Department of Reproductive Health and Research; 2015.
10. Richards MK, Flanagan MR, Littman AJ, Burke AK, Callegari LS. Primary cesarean section and adverse delivery outcomes among women of very advanced maternal age. J Perinatol. 2016; 36(4):272-7. doi: 10. 1038 /jp. 2015.204. Epub 2016.

11. Klemetti R, Gissler M, Sainio S, Hemminki E. At what age does the risk for adverse maternal and infant outcomes increase? Nationwide register-based study on first births in Finland in 2005-2014. Acta obstetricia et gynecologica Scandinavica. 2016; 95 (12): 136875.

12. Bayrampour H, Heaman M, Duncan KA, Tough S. Advanced maternal age and risk perception: a qualitative study. BMC Pregnancy Childbirth. 2012; 12(1): 100. doi: 10.1186/1471-2393-12-100.

13. Declercq E, Mac Dorman M, Osterman M, Belanoff C, Iverson R. Pre-pregnancy obesity and primary cesareans among otherwise low-risk mothers in 38 US states in 2012. Birth. 2015;42(4):309-18. doi: 10.1111/ birt. 12201. Epub 2015 Oct 21.

14. Oakley L, Penn N, Pipi M, Oteng-Ntim E, Doyle P. Risk of Adverse Obstetric and Neonatal Outcomes by Maternal Age: Quantifying Individual and Population Level Risk Using Routine UK Maternity Data. PLoS One.2016;11(10):e0164462. doi: 10.1371/journal. pone. 0164462. eCollection 2016.

15. Timofeev J, Reddy UM, Huang CC, Driggers RW, Landy HJ, Laughon SK. Obstetric complications, neonatal morbidity, and indications for cesarean delivery by maternal age. Obstet Gynecol. 2013;122 (6): 1184-95. doi: 10.1097/ AOG. 0000000000000 017.

16. Cleary-Goldman J, Malone FD, Vidaver J, Ball RH, Nyberg DA, Comstock $\mathrm{CH}$, et al. Impact of maternal age on obstetric outcome. Obstet Gynecol. 2005; 105(5): 983-90. doi: 10. 1097/01. AOG. 0000158118. 75532.51

17. Robson M. Classification of caesarean sections. Fetal Matern Med Rev 2001;12:23-39. doi: https://doi. org/10.1017/S0965539501000122

18. J Thomas and the Royal College of Obstetricians and Gynaecologists, clinical effectiveness support unit. The national sentinel caesarean section audit report. London; RCOG press, 2001. 


\section{Original Research Article}

19. Anderson GM, Lomas J. Determinants of the increasing cesarean birth rate. Ontario data 1979 to 1982. N Engl J Med. 1984;311(14):887-92. doi:10. 1056/ NEJM198410043111405

20.Karim F, Ghazi A, Ali T, Aslam R, Afreen U, Farhat R. Trends and determinants of ceasarean section. Surgery Pakistan. 2011;16:1

21. Patel RR, Peters TJ, Murphy DJ; ALSPAC Study Team. Prenatal risk factors for Caesarean section. Analyses of the ALSPAC cohort of 12,944 women in England. Int J Epidemiol. 2005;34(2):353-67. Epub 2005. DOI:10.1093/ije/dyh401

22. Al-Mulhim A. Factors Affecting the Rate and the Indications of Primary Caesarean Section. Bahrain Med Bul. 2001;23(4):160-2.

23. Stivanello E, Rucci P, Lenzi J, Fantini MP. Determinants of cesarean delivery: a classification tree analysis. BMC Pregnancy Childbirth. 2014 28;14(1): 215. doi: 10.1186/1471-2393-14-215.

24. Gutema H, Shimye A. cesarean section and associated factors at mizanaman general hospital, southwest Ethiopia. J Gynecol Obstet. 2014;2(3):37-41. doi: 10.11648/j.jgo.20140203.12

25. D'orsi E, Chor D, Giffin K, Angulo-Tuesta A, Barbosa G, Sousa Gama A, et al. Factors associated with cesarean section in public hospial in Rio de Janeiro, Brazil. Artigo Article. 2006;22(10):2067-78. doi: $10.1186 / \mathrm{s} 12978-015-0114-8$
26. Patel RR, Peters TJ, Murphy DJ; ALSPAC Study Team. Prenatal risk factors for Caesarean section. Analyses of the ALSPAC cohort of 12,944 women in England. Int J Epidemiol. 2005;34(2):353-67. Epub 2005 Jan 19. doi:10.1093/ije/dyh401

27. Greenberg MB, Cheng YW, Sullivan M, Norton ME, Hopkins LM, Caughey AB. Does length of labor vary by maternal age? Am J Obstet Gynecol. 2007; 197(4):428.e1-7. doi:10.1016/j.ajog.2007.06.058

28. Mary N, Judith U, Hibbard M. Contemporary Labor Patterns and Maternal Age. Obstet Gynecol. 2013; 122 (5): 1018-2. doi: 10. 1097/AOG. 0b013e 3182a9c $92 \mathrm{c}$

29. Alrowaily M, Alsalem F, Abolfotouh M. Cesarean section in a high-parity community in Saudi Arabia: clinical indications and obstetric outcomes.BMC Pregnancy Childbirth. 2014;14(92):1471-2393. doi: https:// doi.org/10.1186/1471-2393-14-92

30. Tsega F, Mengistie B, Dessie Y, Mengesha M. Prevalence of Cesarean Section in Urban Health Facilities and Associated Factors in Eastern Ethiopia: Hospital Based Cross Sectional Study. J Preg Child Health. 2015;2(3):169. doi: 10.4172/2376-127X. 1000169

31. Dewhurt; Textbook of Obstetrics and Gynaecology for Postgraduates (English), Blackwell publishing, 5thEdn, 1995; 392

\section{How to cite this article?}

Nair R.V, Sowbharnika C.P, Seetha P.M. A clinical study on indications for caesarean section among primigravida in a tertiary care centre.Obs Rev: Jobstet Gynecol 2019;5(2):119-124.doi:10.17511/joog.2019.i02.06. 